\title{
Analysis on the Regional Public Governance Path under the View of Cooperation Network
}

\author{
Ren Yinan ${ }^{1}$,Zou Zaijin ${ }^{2}$ * \\ ( ${ }^{1,2}$ School of Public Administration, Yunnan University of Finance and Economics, Yunnan, P. R. China, \\ 650221) \\ (E-mail: ${ }^{1892905976 @ q q . c o m, ~}{ }^{2}$ spa3238@163.com)
}

\begin{abstract}
The increasing regional cooperation has continuously strengthened the cooperation and communication between countries. However, due to the influence of the specific environment, the approaches to public issues and public affairs totally vary from country to country. So the cooperation network governance mode emerging in this situation focuses not only on the intergovernmental cooperation, but also on the positive interaction between the government and the third sectors as well as the citizens. This paper mainly aims at the current regional public governance difficulties, and puts forward to a new approach, the Cooperation Network Governance Mode, and analyzes the problems in the utilization of the governance mode, and at last proposes some countermeasures to them.
\end{abstract}

Key words: Regional Governance, Cooperation Network, Public Affairs, Multiple Subjects

\section{Introduction}

With the increasing international contact and communication, regional cooperation has also increased so much, but focusing only on the interaction and communication between governments, while ignoring the participation of some third sectors and citizens within the region. Therefore, with the economic globalization and the expectation of the better communication and cooperation between countries, the traditional "bureaucracy" governance mode led by the government has become unable to adapt to the development of regional cooperation anymore and the regional public governance concept has also changed, thus forming a new governance mode, the multi-level, multi-center and multi-subject cooperation network.

Regional public governance is the specific application of the governance theory in regional public affairs management ${ }^{[1]}$, which is also a network management system formed through the mutual cooperation of the government and the public. The Cooperation network has overall considered the utilization of the governmental and non- governmental management modes ${ }^{[2]}$. Generated under the globalization and the informatization, the cooperation network governance theory has also confronted lots of difficulties, meanwhile, putting forward to some public governance implications ${ }^{[3]}$. Wallis had summarized the features of the new regionalism that it was a sort of governance but not management, inter departmental rather than in a single department, cooperation but not coordination, a process but not a structure, and a network structure but not an informal structure ${ }^{[4]}$. In Chinese regional governance practice, the embedded relationships among local governments have formed multiple regional cooperation networks, such as the cooperative networks provided by the public services of the evolution of cooperation, the overall network structure and the internal characteristics ${ }^{[5]}$. With the core concept of social network, Feiock presents the local government cooperation relationship and the positive correlation of the weak ties bridging, strong ties cluster and the cross-border interactive relationship between the stable local governmental cooperation and the overall network. He also thinks both the decentralization of authority and the 
progressive joint will promote the formation of a specific regional governance mechanism ${ }^{[6]}$.

To sum up, there have been so many literature works studying the cooperation network of the regional public governance from the theoretical and practicing levels, and discussing the multiple subjects' expression forms, the organizations and the management mechanisms in the regional public governance activities, but paying little attention to the study of the multiple subjects' composite states and the mutual cooperation methods. In view of this, this paper mainly focuses on the regional cooperation network as the research object, analyzing its research background, development trend, difficulties and the approaches to those problems, and putting forward to the multi-subject cooperation network governance mode.

\section{Difficulties of the Regional Public Governance} and Approaches selection

When it comes to the multi-subject governance, we will have to admit that with the development of the current economic globalization, the regional cooperation has also gradually increased, so have the corresponding public affairs and public issues, which have brought about many difficulties during the regional public governance.

\subsection{Difficulties of Regional Public Governance}

The development of regional cooperation needs the co-governance from multiple subjects. But the traditional approaches of government management and the public governance have been unable to make effective governance toward the public affairs and public issues within the region, due to its single governance pattern, the only perspective of the government and the neglect of the supply of the public goods out of the government. This traditional governance mode only pays attention to the inter governmental cooperation development while ignoring the participation of the market and civil society, which can be made up through civil social governance, though confronting the situation of the resource scarcity in all aspects and the communication obstruction because of the lack of government support. It is the failure of government management and civil society governance that provides a sufficient reason for the formation of the governance mode of cooperation network.

\subsection{Approaches: Cooperation Network Governance Mode}

In view of the existing difficulties during the regional public governance, we've carried out the new approach, the cooperation network governance mode, with which the government and the third sector and the citizens mutually cooperate to realize the public interests and to deal with the public affairs. It not only includes the mutual cooperation between governments, but also integrates the participation of some third sectors and citizens in regional public affairs governance, so that it has made the regional public governance more effective, and has become the main governance mode at present.

With the governance mode of cooperation network, governments and the third multinational sectors and citizens together share the public power and provide the public goods to the international community through communication and exchanges, so that they can adjust their participation in the precondition of respecting the interests of both sides, so as to promote regional cooperation and development among countries. The governance mode of cooperation network can help to accomplish the regional public governance and to realize the social public interests in an interdependent environment by overcoming 
their respective limitations and restraining their unreasonable demands. The application of the new governance mode can also make the communication between the participants in regional cooperation more effective, thereby reducing the expenditure and costs during the cooperation and transaction, and creating more opportunity costs; also, a good self-supervision mechanism between subjects can be formed in the regional public governance process, thus lowering the supervision costs in the process of public governance, making full use of more resources into the governance of the regional public affairs, and also improving the efficiency of public governance.

\section{The Existing Problems of Cooperation Network} during the Regional Public Governance

The governance mode of cooperation network has been widely used in regional cooperation currently, but there are still many shortcomings and deficiencies mainly in the following aspects.

\subsection{Influenced by the Traditional System, and a}

\section{Lack of Independence}

At present, the governance mode of cooperation network is still faced with the difficulties of independence, legitimacy and representativeness. The impact of the traditional bureaucratic system and the unbalance caused by the development of globalization both lead to a very big difference in the development scales and influence between different subjects. The traditional International cooperation always takes the government as the leading position, while with the governance mode of cooperation network multiple subjects jointly participate in providing public goods and managing public affairs. On the one hand, apart from the government, other participants, including non-governmental and citizen organizations, need great financial support to establish, operate and manage the organizations. And they still have great dependence on the government in public governance, which not only seriously influences the operation of the governance mode of cooperative network, but also brings about the difficulties to the democratization among subjects. On the other hand, those participants have limited human and material resources, leading to the imperfection of the public governance of the nongovernmental organizations, and their large demands of governmental support and help on the purpose to gradually realize the maximization of the public interests.

\subsection{Liability Concerns Caused by Unclear} Allocation of Responsibilities

Liability concerns are always the unavoidable problems during the public governance. In the process of cooperation network governance, government, the third sectors and citizens share not only the power to deal with the public affairs, but also the public responsibility. In the traditional bureaucratic system, government could be regarded as the only bearer of the public responsibility. As the master of public power, the government is expected to provide public goods and to bear the public responsibility while being entitled to the public power. But in the process of cooperation network governance, apart from the government, there are the third sectors and citizens who jointly participate in the governance, so that the public responsibility has also been shared, and at the same time has arose the bad situation of unclear allocation of responsibilities which are also difficult to distinguish. 


\subsection{The Legitimacy Problem Caused by the} devolution of Administrative Power to the Lower Levels

The legitimacy problem is essentially the public's identity crisis towards the cooperation network. On the one hand, in an interdependent environment, the government and the third sectors jointly deal with the public affairs by providing public goods and performing the public power, which has caused many people's questioning of the legitimacy. Some third sectors hope to obtain more public power so much that they are too eager to perform themselves, but because of their imperfect legal system, the public doubt so much about their legitimacy, which has also brought a huge crisis of confidence to the cooperation network. On the other hand, in the cooperative governance, many public goods are provided by the third sectors, which have been accepted by the public and thus have reduced the authority of the government. The public even question whether the government has got the power to deal with the public affairs or not.

\subsection{The Imperfection of the Relevant Legal System of the Cooperation Network}

In the process of cooperation network governance, the government, the third sectors and the citizens jointly participate in the governance of public affairs. Apart from the government, the public often question the legitimacy of the third sectors' execution of the public power and the provision of public goods, leading to the lack of the confidence of the cooperation network. It has become a focus of public concern that whether those third sectors have the capability of sharing the public responsibilities. As a new governance mode, cooperation network is short of correlative guidelines in the management of public affairs, with the imperfect legal system of the execution of the public power. The government delegate power to lower levels and the other participants are supposed to properly exercise the public power, to provide public goods under the premise of legitimacy, and to imperfect the relevant laws and regulations as soon as possible.

\section{Countermeasures to Imperfect the Regional} Public Governance Cooperation Network

In view of the above shortcomings and deficiencies, we have proposed the corresponding improving countermeasures in the utilization of the current cooperation network governance mode.

\subsection{The Country Should Give Sufficient Support}

Cooperation network governance is essentially the management of public affairs involved in multiple subjects in the interdependent environment. In the process of participatory governance, the government has been changed from the dominant position to the coordinative position, while the other subjects, including the third sectors and citizens, have been changed from the governed to the manager. Therefore, in order to operate the cooperation network smoothly, the country should give the other subjects sufficient support of the human, material and financial resources, so as to reduce their excessive dependence on government, to enhance the independence of the third sectors and the citizens' participation in public governance, and to ensure better operation of the cooperation network.

In an interdependent environment, the cooperation network governance can be carried out smoothly only under the premise of democracy and equality. As the participants, the third sectors and citizens should improve their understanding of cooperation network, enhance their own capability construction, and strengthen the personnel training. Also, they should 
avoid excessive dependence on the government, so as to improve their own independence in the public governance.

\subsection{To Adjust the Orientation of Government} Functions

Since the governance mode of cooperation network is composed of multi subjects who jointly participate in public affairs and public power, the public liabilities should be also shared. As the main subjects of the cooperation network, the government, the third sectors and citizens are supposed to clearly divide their responsibilities, so as to achieve the integration of power and responsibility. Also, the corresponding system of public liability should be improved, so should the subjects' capability of taking the public responsibility. Make sure that they are clear about their own responsibilities and how to bear them while possessing more and more public power.

In terms of the liability concerns, we should pay much attention not only to the division of the responsibilities, but also to the cultivation of the awareness of the third sectors and the citizens, who as the subjects of the cooperation network though, haven't got great own construction and sufficient awareness of public affairs governance. Therefore, in addition to the improvement of the public responsibility system, we also need to do moral and ideological work for those subjects and to strengthen their ethic construction, so as to make them enhance their own public awareness, and to take public responsibility consciously.

\subsection{To Develop Mutual Cooperative Trust}

In the process of cooperation network governance, the government needs to delegate power to the other subjects and to provide public goods and deal with public affairs jointly with them, which could greatly reduce the authority of the government, and also lead to the public's doubt about the legitimacy of other subjects' execution of public power. Cooperative trust is the core of the multi-subject public governance, and also is the premise to maintain cooperation network governance. We should develop the mutual cooperative trust, increase the public trust on the government and other subjects, and maintain the cooperative trust between the government and the third sectors and the society, as it is conducive to the maintenance of the authority of the government, to the legitimacy of other subjects' execution of public power, to the development of the public's confidence on the government and other subjects, to the smooth operation of the cooperation network, to the development of the cooperative trust between the government and other subjects, and to the formation of the good environment of cooperation and trust.

\subsection{To Improve the Legal System Construction}

As the subjects of cooperation network governance, both the government and non-government sectors should establish a complete set of regulations and norms, so as to supervise and restrict their execution of public power. With the change of the public governance mode from government's dominant governance to the multi-subject governance, those non-government sectors and citizens have not been accepted by the public to exercise public power, due to their imperfect legal system and not standard norms of behavior. Therefore, the government, as the representative of public power, should help the other subjects to formulate relevant rules and regulations to make sure that they act in accordance with specific norms and standards and those they can maintain their legitimate rights and interests in the process of public governance. As the subjects of cooperation network governance, the government, nongovernment sectors and citizens should mutually 
restrict and supervise, trust and cooperate with each other, so as to provide better and more acceptable public governance to the public.

\section{Conclusion}

The regional public governance has transferred from the traditional "bureaucracy" to the "multi-subject" cooperation network governance, with which, the government has changed its dominant position to the multi-level and multi-subject participation in the public governance, not only paying attention to the mutual cooperation between governments, but also emphasizing the participation of the third sectors and citizens within the region. Thus the cooperation network has become a new approach to the regional public governance with its great necessity and feasibility in public governance, promoting the international development and cooperation, improving the efficiency of public governance, and helping to form the democracy and equality. In the process of public governance, cooperation network has also confronted with many difficulties, which can be alleviated by clearly dividing public responsibilities, enhancing the moral idea of the subjects, strengthening the construction of laws and regulations, and promoting the development of cooperation network.

\section{Reference}

[1]Chen Ruilian, Yang Aiping. From the Regional Public Management to the Study of Regional Governance: The Historical Transformation [J]. Nankai Journal (Philosophy and Social Sciences), 2012 (2) : 48-57 (In Chinese)

[2]ChenZhenming. Principles of Public Management [M]. Beijing: China Renmin University Press, 2003:75. (In Chinese)
[3]Wang Ruihua. Difficulties and Enlightenment of the Theory of Cooperation Network Governance [J]. Journal of Southwest University of Political Science and Law, 2005 (4) : 23 (In Chinese)

[4] Wallis A D. The third wave: current trends in regional governance [J]. National Civic Review, 1994(3):290-310

[5]Li Xiang, Yan Guangle. Empirical Analysis of the Regional Public Governance Cooperation Network: Taking the Yangtze River Delta Urban Agglomeration as an example [J]. 2013 (5): 77.(In Chinese)

[6] Feiock R C. Rational choice and regional governance [J].Journal of Urban Affairs,2007(29):47-63.

[7] Song Qiang, Hu Haibo, Xia Xuexian. Global Civil Society and the International Cooperation in the Age of Globalization [J]. 2013 (01) : 7. (In Chinese)

[8] Zheng Hong. The Analysis of the Approach to the Public Management Innovation from the Perspective of Regional Integration [J]. 2013 (4): 124. (In Chinese)

[9] Zhang Ling, Li Haoliang. The Discussion on the Institutional Innovation of Regional Public Management [D]. 2013 (01): 244. (In Chinese)

[10] Lv Jun. The Analysis on the Institutional Innovation of Regional Public Management [J]. Managerialist, 2013 (10) : 54. (In Chinese) 